Check for updates

Cite this: RSC Adv., 2018, 8, 3716

\title{
Probing the surface structure of hydroxyapatite through its interaction with hydroxyl: a first- principles study $\uparrow$
}

\author{
Xian Wang, Li Zhang, ${ }^{*}$ Zeyu Liu, Qun Zeng, (D) Gang Jiang and Mingli Yang (D)*
}

\begin{abstract}
Understanding the interaction of the hydroxyapatite ( $\mathrm{HAp}$ ) surface with hydroxyl originating from either the alkalescent physiological environment or HAp itself is crucial for the development of HAp-based biomaterials. Periodical density functional theory calculations were carried out in this study to explore the interaction of the HAp (100), (010) and (001) facets with hydroxyl. Based on a comparison study of Ca-rich, $\mathrm{PO}_{4}$-rich and $\mathrm{Ca}-\mathrm{PO}_{4}-\mathrm{OH}$ mixed surfaces, the interaction pattern, interaction energy and effect of an additional water molecule on the $\mathrm{Ca}-\mathrm{OH}$ interaction were comprehensively studied. The formation of $\mathrm{CaOH}$ on the Ca-rich surface was energetically favored on (100) and (001), while $\mathrm{Ca}(\mathrm{OH})_{2}$ was energetically favored on (010). The $\mathrm{Ca}$-water interaction was competitive, but had lower interaction energy than $\mathrm{Ca}-\mathrm{OH}$. Furthermore, $\mathrm{Ca}-\mathrm{O}$ bonding and its influence on the $\mathrm{OH}$ stretching vibration were analyzed. Our calculations suggest that the hydroxyl-coated surface structure is more appropriate than the commonly used Ca-terminated surface model for studying HAp surface activity in its service environments.
\end{abstract}

Received 7th December 2017 Accepted 2nd January 2018

DOI: $10.1039 / c 7 r a 13121 f$

rsc.li/rsc-advances and Rivas et al. ${ }^{18}$ investigated the structure of the HAp (010) and (100) surfaces via X-ray diffraction (XRD), XPS and Fourier transform infrared (FTIR) spectroscopy, and addressed their strong interaction with biological media. A number of computer simulations ${ }^{19-31}$ have been conducted to investigate the HAp surface structure and its interaction with various biomolecules using stoichiometric or nonstoichiometric HAp as a model surface in the first-principles or force-fields level. Slepko et al. ${ }^{22}$ identified the low energy surface orientations and stoichiometry under diverse chemical environments using a slab model. Almora et al. ${ }^{23}$ Filgueiras et $a l .{ }^{24}$ and Rimola et $a l .{ }^{25}$ studied the interaction of the HAp surface with citric, glycine, lysine, and proline, and demonstrated that the HAp surface substantially affects the interaction patterns, amino acid conformation, and interaction strength. Molecular dynamics simulations ${ }^{26-30}$ with various force field parameters indicated that surface $\mathrm{Ca}^{2+}$ and $\mathrm{PO}_{4}{ }^{3-}$ ions serve as effective adsorption sites binding with adsorbates, and the adsorption is facilitated by the ionic nature of the HAp surface. In most calculations, a Ca-exposed surface was used as the HAp model to explore its interaction with biomolecules. Evidently, studies on the HAp surface-adsorbate interaction shed light not only on its adsorption behaviors, but also on the details of the HAp surface structure.

Various studies have been devoted to the interaction of the HAp surface with hydroxyl originating from either HAp itself or the environment. The chemical adsorption of water molecules on the HAp surface generates and leaves hydroxyl ions on its surface. ${ }^{7,27,31,32}$ The existence of hydroxyl groups on the HAP surface significantly alters its activity. Hokkanen et al. ${ }^{33}$ 
characterized the electrostatic attraction between surface hydroxyl groups and other adsorbates. Chen et al. ${ }^{34}$ studied the adsorption mechanism of sulfate-doped hydroxyapatite and found that the hydroxyl groups on the surface cooperatively enhanced fluoride removal. The hydroxyl-terminated (010) surface was found ${ }^{7}$ to be stable and inactive for water decomposition. The treatment of $\mathrm{NaOH}$ or $\mathrm{KOH}$ on natural bone whose main component is HAp led to the growth of HAp crystallites $^{35}$ and a shape variation from B-type to A-type. The enrichment of hydroxyl on the HAp surface significantly promoted collagen self-assembly, fibrous network formation and cell adhesion. ${ }^{36}$ The coating of hydroxyl groups on the HAp surface provides an effective way to functionalize the HAp surface since many other species may link directly with the hydroxyls. ${ }^{37,38}$

Since HAp-based biomaterials are usually applied in alkalescent physiological environment, ${ }^{\mathbf{3 9 , 4 0}}$ hydroxyl groups play an important role in the determination of HAp surface activity; however, knowledge on the surface-hydroxyl interaction is still scarce. Calcium or phosphate-terminated exposed surfaces sliced from the HAp crystal are often used to represent the surface structure of HAp. However, this surface model is not supported by some experimental and computational results. Kolmas et al. ${ }^{\mathbf{4 1}}$ identified structural hydroxyl groups and surface $\mathrm{P}-\mathrm{OH}$ groups with near-infrared spectroscopy. Osman et al. ${ }^{\mathbf{1 4}}$ and Bertinetti et al. ${ }^{42}$ found no $\mathrm{Ca}(\mathrm{OH})_{2}$ formation on the HAp surface with a developed NMR strategy. Wang et al. ${ }^{43}$ predicted at the force-field level the formation of $\mathrm{CaOH}$ and $\mathrm{POH}$ on the HAp surface, which exert considerable influence on the adsorption energy of proteins. In our previous studies, ${ }^{26,43}$ we noted via an annealed MD simulation that hydroxyl groups have a tendency to cap exposed surface calcium ions. In this study, we conduct a first-principles study on the HAp surface-hydroxyl interaction. As revealed below, a strong $\mathrm{Ca}-\mathrm{OH}$ interaction is noted. The surface reorganization caused by $\mathrm{CaOH}$ or $\mathrm{Ca}(\mathrm{OH})_{2}$ formation is energetically favorable on the surface, but the formed species are different and dependent on the facet. Moreover, water molecules are competitive with hydroxyl and weaken to some extent the $\mathrm{Ca}-\mathrm{OH}$ interaction. Based on our calculations, a hydroxyl-coated surface structure is suggested to replace the commonly used Ca-terminated surface model for HAp in its service environment.

\section{Computational method}

HAp has two phases, hexagonal and monoclinic, in crystal. These two phases exhibit parallel behaviors in many cases and the former is often selected in many studies. ${ }^{44}$ Fig. 1A displays the crystal structure of hexagonal HAp, where 44 atoms are in a unit cell. The crystal contains tetrahedral phosphate groups, hydroxyl groups, and calcium ions. There are two types of $\mathrm{Ca}$ ions, which are denoted as $\mathrm{Ca}(\mathrm{I})$ and $\mathrm{Ca}(\mathrm{II})$, in the cell. $\mathrm{Ca}(\mathrm{I})$ is arranged in single atomic columns parallel to the $c$ axis and is surrounded by phosphate tetrahedra, whereas the $\mathrm{Ca}$ (II) ions form a hexagonal column, at the center of which are the hydroxyl groups.

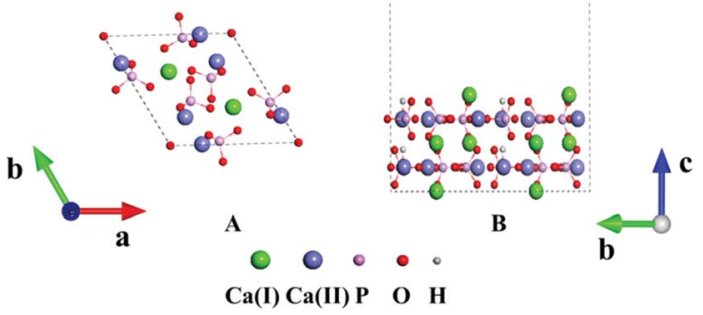

Fig. 1 (A) Crystal structure of HAp. (B) Slab model of the HAp surface.

The (100), (010) and (001) facets were constructed by slicing the crystal structure. For each facet, three slab models with different exposed atoms were constructed. Thus, nine surface models in total were studied for HAp in this work. The chemical components were kept stoichiometric in all the slab models. A 1 $\times 2 \times 1$ supercell was chosen in the relaxation for the lattice constants, and the surface was modeled with $1 \times 2 \times 1$ supercells separated with $15 \AA$ thick vacuum layers, as depicted in Fig. 1B. The vacuum layers were stacked along the direction perpendicular to the slab. In the calculations for the HAp surfaces, atoms in the bottom unit were fixed to mimic the real inner crystalline HAp, while all the atoms in the upper unit were allowed to relax. Since both calcium and phosphate ions are highly charged, they might form a strong artificial dipolar electric field in the slab model. Thus, a dipolar correction ${ }^{45}$ along the normal direction of the slabs was introduced to remove the polarization effect caused by the slab and its periodic images.

Three Ca-rich surfaces, one for each facet, among the nine surface models were selected to explore their interaction with hydroxyl and water. Two Ca ions were exposed for all three surfaces. Although the hydroxyl may attack several sites on the surface, we found it always prefers the Ca ions, which has also been addressed in other studies. ${ }^{26,43}$ The hydroxyl groups have several interaction patterns with the surface Ca ions. As shown in Fig. 2, three types of hydroxyl-Ca interaction patterns on the (001) surface were designed. In the first pattern (F7A), one hydroxyl binds to one Ca ion on the surface. In the second (F7B), two hydroxyls bind to two different $\mathrm{Ca}$ ions, while in the last (F7C) two hydroxyls bind to one Ca ion. Additionally, to examine the effect of water on the hydroxyl-Ca interaction, one water molecule was added to the model, as shown in Fig. 3, in which three patterns, W7, W7A and W7B are presented. Similar patterns were designed for the hydroxyl and water adsorption on the (010) and (100) facets, which are presented in Fig. S1 and $\mathrm{S} 2$ in the ESI. $\dagger$ In the systems with hydroxyl groups, protons were introduced to balance the system. To avoid their influence on hydroxyl adsorption, the protons were added to the phosphate groups at the lower surface.

All calculations were carried out with the density functional theory (DFT) method in the Vienna ab initio simulation package (VASP) code. ${ }^{46}$ The generalized gradients approximation (GGA) of the Perdew-Wang 1991 (PW91) functional was employed with the projection augmented wave (PAW) type of 

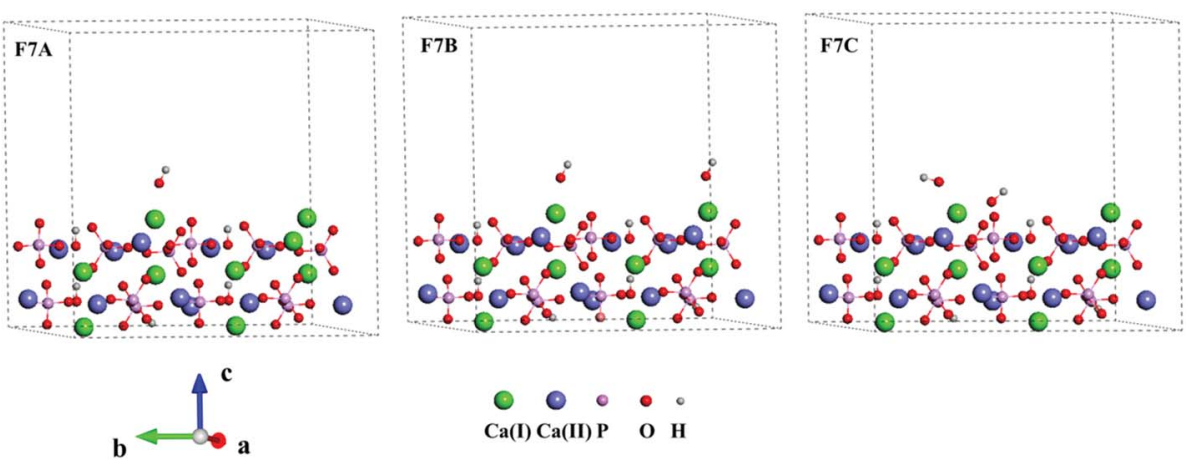

Fig. 2 Interaction patterns of hydroxyls (F7A, F7B and 7C) on the Ca-rich (001) surface of HAp.
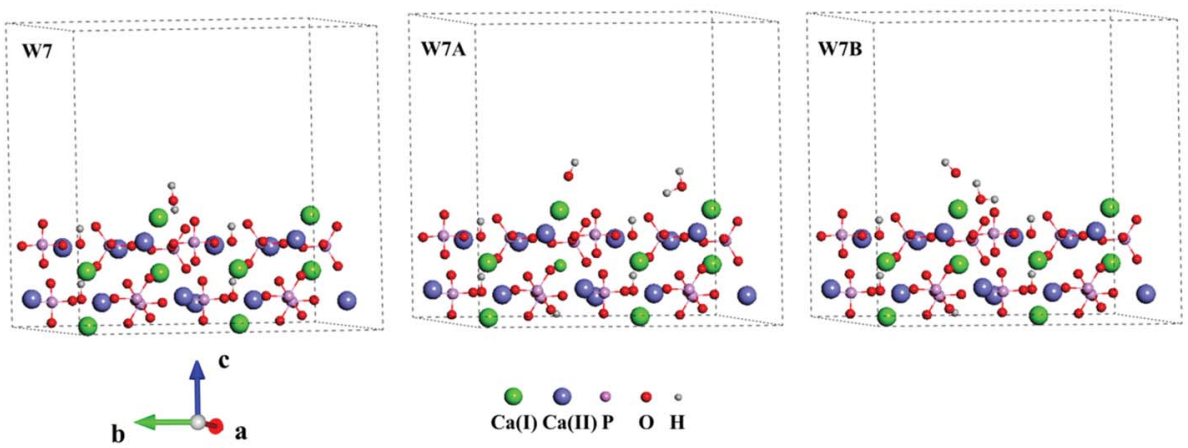

Fig. 3 Interaction patterns of the water molecule (W7), hydroxyl and water (W7A and W7B) on the Ca-rich (001) surface of HAp.

pseudopotential. ${ }^{47}$ The energy cut-off was set to $550 \mathrm{eV}$ in all calculations. A $2 \times 2 \times 2$ Monkhorst-Pack $k$-point mesh was applied to the Brillouin zone sampling of the HAp single cell, while a $2 \times 2 \times 1$ mesh was chosen for the slab models. The atomic configurations were relaxed with the conjugate-gradient (CG) approach. ${ }^{48}$ The force convergence was set to be $0.001 \mathrm{eV}$ $\AA^{-1}$ for successive structures. Furthermore, harmonic vibrational frequency calculations were performed to ensure that the relaxed structures were local minima on the potential energy surface.

\section{Results and discussion}

The optimized lattice constants of the HAp crystal were given in Table 1, together with the results of some other computational and experimental studies. ${ }^{23,49-51}$ The deviations are less than $0.05 \AA$ for $a, b$ and $c$, compared to the measurement, and our

Table 1 Lattice parameters of the hydroxyapatite crystal

\begin{tabular}{|c|c|c|c|c|c|c|}
\hline & $a(\AA)$ & $b(\AA)$ & $c(\AA)$ & $\alpha\left(^{\circ}\right)$ & $\beta\left(^{\circ}\right)$ & $\gamma\left({ }^{\circ}\right)$ \\
\hline This work & 9.373 & 9.373 & 6.855 & 90 & 90 & 120 \\
\hline Astala et al. ${ }^{50}$ & 9.360 & 9.360 & 6.990 & 90 & 90 & 120 \\
\hline Ulian et $a ._{.}^{51}$ & 9.430 & 9.430 & 6.891 & 90 & 90 & 120 \\
\hline Almora-Barrios et al. ${ }^{23}$ & 9.403 & 9.403 & 6.954 & 90 & 90 & 120 \\
\hline Renaudin et $a l .{ }^{49}$ & 9.424 & 9.424 & 6.897 & 90 & 90 & 120 \\
\hline
\end{tabular}

calculations agree well with other computations. ${ }^{23,50,51}$ Generally, the hydroxyl and phosphate groups retain their orientations as in the measurement. The $\mathrm{O}-\mathrm{H}$ and $\mathrm{P}-\mathrm{O}$ bond lengths are $0.978 \AA$ and $1.535 \AA$, which match well with the measurement (0.971 $\AA$ and $1.540 \AA)$, respectively. ${ }^{10}$

The nine constructed HAp surfaces (SF1-9) were optimized and presented in Fig. S3. $\uparrow$ For the (100) facet, SF1, SF2 and SF3 are terminated with Ca-rich, $\mathrm{PO}_{4}$-rich and $\mathrm{Ca}-\mathrm{PO}_{4}-\mathrm{OH}$ surfaces, respectively. $\mathrm{Ca}-\mathrm{PO}_{4}-\mathrm{OH}$ denotes the situation where $\mathrm{Ca}, \mathrm{PO}_{4}{ }^{3-}$ and $\mathrm{OH}$ are all on the surface. Similar surface characteristics are observed for SF4, SF5 and SF6 on the (010) facet, and SF7, SF8 and SF9 on the (001) facet. The stability of a surface is usually measured according to its surface energy, which corresponds to the energy required to cleave the bulk crystal and to expose its surface. Surface energy was evaluated computationally as follows: ${ }^{52}$

$$
\gamma=\left(E_{\text {slab }}-n E_{\text {bulk }}\right) / 2 \mathrm{~A}
$$

where, $E_{\text {slab }}$ and $E_{\text {bulk }}$ are the total energies of the slab model and the unit cell, respectively. $A$ is the surface area and the factor 2 is ascribed to the upper and lower surfaces which have the same surface area. $n$ stands for the number of HAp crystal units in the slab model. The calculated surface energies of the nine surface structures are shown in Table 2. Leeuw et al., ${ }^{53}$ Filgueiras et $a .^{24}$ and Slepko et al. ${ }^{22}$ computed the surface energy for various facets of HAp, which are also listed in Table 2. Notably, the computed surface energies vary in a wide range. The differences may originate from different facets and exposed 
Table 2 Calculated surface energies $\left(\gamma\right.$, in $\left.\mathrm{J} \mathrm{m}^{-2}\right)$ of various hydroxyapatite surfaces

\begin{tabular}{|c|c|c|c|c|}
\hline Pattern $^{a}$ & Facet & Termination & This work & Other studies \\
\hline F1 & $(100)$ & Ca-rich & 1.42 & $1.22^{b}($ ref. 24$)$ \\
\hline F2 & $(100)$ & $\mathrm{PO}_{4}$-rich & 1.56 & $1.33^{b}$ (ref. 24$)$ \\
\hline $\mathrm{F} 4$ & $(010)$ & Ca-rich & 1.35 & $1.14^{c}($ ref. 54$), 1.41^{d}($ ref. 51$), 1.76^{e}$ (ref. 50) \\
\hline F5 & $(010)$ & $\mathrm{PO}_{4}$-rich & 1.18 & $0.99^{c}$ (ref. 54$), 1.28^{e}$ (ref. 50), $1.16^{f}$ (ref. 53) \\
\hline F6 & $(010)$ & $\mathrm{Ca}-\mathrm{PO}_{4}-\mathrm{OH}$ & 1.27 & $1.68^{e}$ (ref. 50) \\
\hline F9 & $(001)$ & $\mathrm{Ca}-\mathrm{PO}_{4}-\mathrm{OH}$ & 1.09 & $1.12^{e}$ (ref. 50) \\
\hline
\end{tabular}

${ }^{a}$ See Fig. S3 for the patterns. ${ }^{b}$ With force-fields. ${ }^{c}$ With B3LYP-D*. ${ }^{d}$ With B3LYP. ${ }^{e}$ With PBE. ${ }^{f}$ With force-fields. ${ }^{g}$ With PW91. ${ }^{h}$ With force-fields.

species, as well as computational approaches. Our calculations are relatively close to their computations for specific surface structures.

The surface energy depends on not only the crystal facet, but also the surface species. For (100) and (001), the $\mathrm{Ca}-\mathrm{PO}_{4}-\mathrm{OH}$ surface is the most stable, followed by the $\mathrm{PO}_{4}$-rich and Ca-rich surfaces. The same order was reported by Slepko et al. ${ }^{22}$ for the HAp (100) and (001) surfaces. For (010), the $\mathrm{PO}_{4}$-rich surface is the most stable, followed by the $\mathrm{Ca}-\mathrm{PO}_{4}-\mathrm{OH}$ and Ca-rich surfaces. Astala et $a .^{50}$ also found that the Ca-rich (010) surface is more active than the $\mathrm{PO}_{4}$-rich surface. Therefore, surfaces with different species may have different stability, and also the same species on different facets. The Ca-rich surfaces generally have high activity toward other molecules with nucleophilic activity, such as hydroxyl and water. Therefore, we therefore focused on the interaction of hydroxyl groups on the Ca-rich surface (SF1, SF4 and SF7) in the subsequent calculations.

The interaction of hydroxyl with the HAp surface was analyzed in terms of interaction pattern and interaction energy. All three patterns, which are denoted as A, B and C, for each facet were relaxed and their interaction energy evaluated as:

$$
E_{\text {int }}=E_{\text {sys }}-\left(E_{\text {slab }}+E_{\text {ads }}\right)
$$

where, $E_{\text {slab }}$ is the energy of the HAp surface slab model, $E_{\text {ads }}$ is the energy of the isolated adsorbate, and $E_{\text {sys }}$ is the energy of the complete system containing the HAp slab and the adsorbate. A

Table 3 Interaction energies ( $E_{\text {int, }}$ in $\mathrm{eV}$ ) of hydroxyl on the (100), (010) and (001) facets in various patterns

\begin{tabular}{lllll}
\hline Pattern $^{a}$ & Facet & $N_{\mathrm{Ca}}{ }^{b}$ & $N_{\mathrm{OH}}{ }^{c}$ & $E_{\text {int }}$ \\
\hline F1A & $(100)$ & 1 & 1 & -1.37 \\
F1B & $(100)$ & 2 & 2 & -2.10 \\
F1C & $(100)$ & 1 & 2 & -1.94 \\
F4A & $(010)$ & 1 & 1 & -1.48 \\
F4B & $(010)$ & 2 & 2 & -2.60 \\
F4C & $(010)$ & 1 & 2 & -2.78 \\
F7A & $(001)$ & 1 & 1 & -1.44 \\
F7B & $(001)$ & 2 & 2 & -2.43 \\
F7C & $(001)$ & 1 & 2 & -2.23
\end{tabular}

${ }^{a}$ See Fig. 2, 3, S1 and S2 for the patterns. ${ }^{b}$ Number of exposed Ca ions binding with hydroxyl. ${ }^{c}$ Number of hydroxyls binding with exposed Ca ion. negative interaction energy indicates a thermodynamically favorable adsorption process. The computed $E_{\text {int }}$ values are given in Table 3, where F1A, F4A and F7A correspond to pattern A on the (100), (010) and (001) Ca-rich facets, respectively. Similar notations are applied to patterns B and C. The $E_{\text {int }}$ of hydroxyl on HAp varies with the facet and pattern. First, the coating of hydroxyl on the exposed surface calcium ion makes the surface structure more stable. All the $E_{\text {int }}$ values are negative and large in magnitude, which indicate a strong interaction between the negatively charged hydroxyl and positively charged surface calcium ion. The $\mathrm{Ca}-\mathrm{OH}$ distances range between 2.12 and $2.38 \AA$ with the characteristic of an ionic bond. Second, for all the three patterns, hydroxyl adsorption is the strongest interaction with the (010) facet, followed by the (001) and (100) facets, which indicates that the three Ca-rich facets have different interaction strengths with hydroxyl. Although all three facets are Ca-rich, the $\mathrm{Ca}$ ions have different environments. On (100), the two $\mathrm{Ca}$ ions sit above four $\mathrm{O}$ atoms of surrounding phosphates. On (010) and (001), the two Ca ions sit above three $\mathrm{O}$ atoms of surrounding phosphates. Moreover, the $\mathrm{Ca}-\mathrm{O}$ distances are quite different on the three facets. As a result, the $\mathrm{Ca}$ ions have different averaged amounts of net charge, $0.51 e$ on (100), $0.99 e$ on (010) and $0.79 e$ on (001), resulting in different interaction strengths on the three facets. Third, the successive adsorption of hydroxyl lowers further the total energy. From pattern A to pattern B or C, $E_{\text {int }}$ increases for all three facets, which is about $0.57-1.3 \mathrm{eV}$. Taking the (001) facet as an example, in pattern $\mathrm{B}$, the second hydroxyl binds with the second $\mathrm{Ca}$ ion, leading to a $\mathrm{Ca}-\mathrm{OH}$ distance of $2.23 \AA$, while the first $\mathrm{Ca}-\mathrm{OH}$ distances varies by about $0.02 \AA$. In pattern $\mathrm{C}$, the second hydroxyl binds with the same $\mathrm{Ca}$ ion. The two $\mathrm{Ca}-\mathrm{OH}$ bonds have similar bond-lengths of 2.25 and $2.26 \AA$, respectively, which are lengthened by $0.03 \AA$ compared to the case of only one hydroxyl. Therefore, the second hydroxyl forms a strong bond with the $\mathrm{Ca}$ ion and enhances the hydroxyl-HAp interaction. Finally, patterns $\mathrm{B}$ and $\mathrm{C}$ are close in $E_{\text {int }}$ magnitude. The differences are 0.06, 0.18 and $0.20 \mathrm{eV}$ for the (100), (010) and (001) facets, respectively, which indicate that these two patterns may coexist under certain conditions. Elliot et al. ${ }^{55}$ suggested the formation of $\mathrm{Ca}(\mathrm{OH})_{2}$-like species on the HAp surface, whereas Osman et al. ${ }^{\mathbf{1 4 4 2 , 4 3 , 5 6}}$ found no $\mathrm{Ca}(\mathrm{OH})_{2}$ but $\mathrm{Ca}(\mathrm{OH})$ formation. Our calculations suggest that the formation of both $\mathrm{CaOH}$ and $\mathrm{Ca}(\mathrm{OH})_{2}$ on the HAp surface is possible. 
The interaction of hydroxyl on the dry HAp surface was analyzed above. In most of its applications, HAp exists in an environment with water. Thus, we used a simple explicit model in which one water molecule was added on the surface to explore the effect of water on the hydroxyl-HAp interaction. The hydroxyl-HAp interaction did not show notable changes when the water molecule is far from hydroxyl. Thus, we focused on the model in which the water molecule binds directly with hydroxyl or its bonded Ca ion. In absence of hydroxyl, the water molecule adsorbs onto the surface by its $\mathrm{O}$ atom attacking the exposed $\mathrm{Ca}$ ion, as displayed in Fig. 3 (7W), S1 (1W) and S2 (4W). $†$ The Ca-O distances are about $2.30 \AA$. Meanwhile, one or two $\mathrm{H}$ atoms form hydrogen bonds with the $\mathrm{O}$ atoms of a nearby phosphate. The hydrogen bonds are 1.50-2.10 ̊ in length. The interaction energies of the water molecule with the facets are given in Table 4 . The (010) facet has the greatest $E_{\text {int }}$ with the water molecule, while (100) has the smallest value, which corresponds well with the order of their surface energies. Our finding is in agreement with many other studies., ${ }^{7,50,54,57}$ The $E_{\text {int }}$ values are 0.78-1.07 eV for the three facets, which are about $0.50 \mathrm{eV}$ less than that of hydroxyl. It is understandable that the negatively charged hydroxyl has stronger interaction with the positively charged $\mathrm{Ca}$ ion than the neutral water molecule.

Fig. 2, 3, S1 and $\mathrm{S} 2 \uparrow$ show the optimized structures of the hydroxyl-HAp-water systems. The water molecule has two options on the surface, interacting with the $\mathrm{Ca}$ ion with or without a hydroxyl, which are denoted as A and B, respectively. In both cases, the co-addition of hydroxyl and one water molecule lowers the total energy and leads to a lower surface energy. The (010) facet has the greatest $E_{\text {int }}$, followed by (001) and (100), which is the same order as that of hydroxyl on the dry HAp surface. In the first case, the water molecule competes with hydroxyl. On (010), the Ca-OH distance changes from $2.12 \AA$ to $2.20 \AA$ after the addition of water. Meanwhile, the water molecule forms a hydrogen bond with the surface phosphate. The addition of a water molecule to some extent weakens the interaction between hydroxyl and surface Ca ion. Table 4 lists the interaction energies of the hydroxyl-HAp-water systems. On (010), the $E_{\text {int }}$ of hydroxyl decreases from $1.48 \mathrm{eV}$ to $1.17 \mathrm{eV}$. In

Table 4 Interaction energies ( $E_{\text {int, }}$ in $\mathrm{eV}$ ) of the hydroxyl and water molecule on the Ca-rich (100), (010) and (001) facets of HAp

\begin{tabular}{|c|c|c|c|c|c|}
\hline Pattern $^{a}$ & Facet & $N_{\mathrm{OH}}^{b}$ & $N_{\mathrm{H}_{2} \mathrm{O}}{ }^{c}$ & $E_{\text {int }}^{d}$ & $E_{\text {int }}^{\prime}{ }^{e}$ \\
\hline W1 & (100) & 0 & 1 & -0.78 & - \\
\hline W1A & $(100)$ & 1 & 1 & -1.84 & -0.96 \\
\hline W1B & (100) & 1 & 1 & -1.76 & -0.88 \\
\hline W4 & (010) & 0 & 1 & -1.07 & - \\
\hline W4A & (010) & 1 & 1 & -2.46 & -1.26 \\
\hline W4B & (010) & 1 & 1 & -2.37 & -1.17 \\
\hline W7 & (001) & 0 & 1 & -0.92 & - \\
\hline W7A & (001) & 1 & 1 & -2.20 & -1.10 \\
\hline W7B & $(001)$ & 1 & 1 & -2.12 & -1.02 \\
\hline
\end{tabular}

Ca ion. ${ }^{d} E_{\text {int }}=E_{\mathrm{HAp}+\mathrm{H}_{2} \mathrm{O}+\mathrm{OH}}-\left(E_{\mathrm{HAP}}+E_{\mathrm{H}_{2} \mathrm{O}}+E_{\mathrm{OH}}\right) \cdot{ }^{e} E_{\text {int }}^{\prime}=E_{\mathrm{HAp}+\mathrm{H}_{2} \mathrm{O}+\mathrm{OH}}$ $-\left(E_{\mathrm{HAP}}+E_{\mathrm{H}_{2} \mathrm{O}}+E_{\mathrm{OH}}\right)$. the second case, water and hydroxyl are on different $\mathrm{Ca}$ ions. The water molecule almost retains its conformer in the absence of hydroxyl. The changes in the $\mathrm{Ca}-\mathrm{OH}$ and $\mathrm{Ca}-\mathrm{OH}_{2}$ distances are less than $0.1 \AA$, and the corresponding $E_{\text {int }}$ of hydroxyl has a very small decrease of $0.22 \mathrm{eV}$. Therefore, the hydroxyl and water molecule may co-adsorb on the HAp surface, and have the option to locate at the $\mathrm{Ca}$ ion without a water molecule.

It has been found experimentally ${ }^{58,59}$ that HAp grows predominantly along the (001) direction, which means that (001) facet is unstable and has stronger interaction with adsorbates. However, in our work, hydroxyl and water molecules have weaker interaction with $\mathrm{Ca}$ ions on the (001) facet than on the (010) facet. It should be mentioned that the computed interaction energies reveal only the nucleophilic activity of surface $\mathrm{Ca}$ ions. The activity of other surface species such as phosphates is not considered. The computed interaction energy is therefore not an indicator of the preferred growth direction of HAp.

The interaction between hydroxyl and the Ca-rich HAp surface was further studied by computing the stretching vibrational frequencies of the $\mathrm{Ca}-\mathrm{O}$ and $\mathrm{O}-\mathrm{H}$ bonds. Table 5 lists the wavenumbers of the $\mathrm{Ca}-\mathrm{O}$ and $\mathrm{O}-\mathrm{H}$ bonds on the dry and hydrated (100), (010) and (001) facets. Although some studies ${ }^{56,57,60,61}$ have characterized the $\mathrm{O}-\mathrm{H}$ vibrational frequency, the motion of the $\mathrm{Ca}-\mathrm{O}$ bond has been seldom studied. The strong adsorption of hydroxyl and water and adsorption on the Ca-rich facets generates stretching vibrational motions for the $\mathrm{Ca}-\mathrm{O}$ bonds with frequencies in the range of $360-450 \mathrm{~cm}^{-1}$ for $\mathrm{Ca}-\mathrm{OH}_{2}$ and $380-550 \mathrm{~cm}^{-1}$ for $\mathrm{Ca}-$ $\mathrm{OH}$. In general, the stretching vibrations of $\mathrm{Ca}-\mathrm{OH}_{2}$ lie at lower frequencies than that of $\mathrm{Ca}-\mathrm{OH}$ in the same surface structure, which corresponds well with the stronger interaction between HAp and hydroxyl. Moreover, for the same pattern, the formed $\mathrm{Ca}-\mathrm{O}$ bonds on the (010) facet stretch at higher frequencies than that on (100) and (001). The frequencies for the F4 and W4

Table 5 Computed stretching vibrational frequencies (in $\mathrm{cm}^{-1}$ ) of the $\mathrm{Ca}-\mathrm{O}$ and $\mathrm{O}-\mathrm{H}$ bonds in the hydroxyl-HAp and hydroxyl-HAp-water systems

\begin{tabular}{llllll}
\hline Pattern & Facet & $\mathrm{Ca}-\mathrm{O}_{\mathrm{H}}$ & $\mathrm{Ca}-\mathrm{O}_{\mathrm{w}}$ & $\mathrm{O}_{\mathrm{H}}-\mathrm{H}$ & $\mathrm{O}_{\mathrm{w}}-\mathrm{H}$ \\
\hline F1A & $(100)$ & 410 & - & 3783 & - \\
F1B & $(100)$ & 407,379 & - & 3746,3723 & - \\
F1C & $(100)$ & 401,396 & - & 3765,3751 & - \\
F4A & $(010)$ & 548 & - & 3863 & - \\
F4B & $(010)$ & 540,509 & - & 3834,3804 & - \\
F4C & $(010)$ & 543,530 & - & 3846,3818 & - \\
F7A & $(001)$ & 480 & - & 3809 & - \\
F7B & $(001)$ & 474,458 & - & 3801,3785 & - \\
F7C & $(001)$ & 451,465 & - & 3799,3804 & - \\
W1 & $(100)$ & - & 360 & - & 3476 \\
W1A & $(100)$ & 389 & 357 & 3743 & 3447 \\
W1B & $(100)$ & 381 & 351 & 3732 & 3432 \\
W4 & $(010)$ & - & 452 & - & 3672 \\
W4A & $(010)$ & 537 & 449 & 3832 & 3631 \\
W4B & $(010)$ & 507 & 442 & 3821 & 3579 \\
W7 & $(001)$ & - & 415 & - & 3586 \\
W7A & $(001)$ & 450 & 396 & 3795 & 3508 \\
W7B & $(001)$ & 445 & 380 & 3786 & 3501
\end{tabular}


series are always higher than that of the F1, W1, F7 and W1 series, which is consistent with their interaction energy orders. On the same facet, the interaction pattern also has an effect on the vibrational frequency. The mono-adsorbed $\mathrm{Ca}-\mathrm{OH}$ bonds in F1A, F4A and F7A have higher frequencies than the di-adsorbed $\mathrm{Ca}-\mathrm{OH}$ bonds in the other patterns. Upon the water addition, the $\mathrm{Ca}-\mathrm{OH}$ bonds exhibit red shifts of $3-35 \mathrm{~cm}^{-1}$. It is clear from the stretching frequencies and their changes that the surface Ca ions have strong interaction with hydroxyl, which is stronger than that between $\mathrm{Ca}$-water, but slightly weakened on the hydrated surface.

The O-H stretching vibrations of the hydroxyl groups on the HAp surfaces vary from $3723 \mathrm{~cm}^{-1}$ to $3863 \mathrm{~cm}^{-1}$. The corresponding frequency of the free hydroxyl is $3696 \mathrm{~cm}^{-1}$, which is in agreement with the previous computation of $3642 \mathrm{~cm}^{-1}$ (ref. 62) and measurement of $3738 \mathrm{~cm}^{-1}$ (ref. 62 and 63). Upon adsorption on the surface, the vibration moves to a lower wavenumber with a shift of $36-167 \mathrm{~cm}^{-1}$. The shifts are dependent on the interaction patterns and facets. The strong $\mathrm{Ca}-\mathrm{OH}$ interaction usually leads to a large red shift. The addition of one water molecule leads to a blue shift in the $\mathrm{Ca}-\mathrm{OH}$ vibration, which results from the weakening of the $\mathrm{Ca}-\mathrm{OH}$ interaction. Experimentally, the band at $3570-3613 \mathrm{~cm}^{-1}$ (ref. 10, 60, 64 and 65) was assigned to column hydroxyl in bulk HAp. Some computational studies by the density function method predicted the $\mathrm{OH}$ stretching frequency at 3757 and $3774 \mathrm{~cm}^{-1}$ in crystal. ${ }^{66,67}$ A wide range of bands, including 3636, 3670, 3680, 3729 , and $3734 \mathrm{~cm}^{-1}$, have been assigned for PO-H on the surface. ${ }^{60}$ The band at $3572 \mathrm{~cm}^{-1}$ was assigned to both column and surface hydroxyl ${ }^{56,60,61}$ when the measurement for surface hydroxyl was carried out upon $\mathrm{CO}_{2}$ adsorption on the HAp surface. Thus, the adsorbed $\mathrm{CO}_{2}$ made the band shift to a low wavenumber.

\section{Conclusion}

Density functional theory calculations with the PW91 functional and PAW pseudopotential were performed to study the bulk and surface structures of HAp, as well as their interaction with hydroxyl groups and water molecules. Our computed lattice parameters and surface structures of pure HAp agree well with previous computational and experimental studies. The interaction patterns of Ca-rich surfaces on the (100), (010) and (001) facets with one or two hydroxyl groups were constructed and optimized using a slab model. Strong bonding between the surface Ca ion and hydroxyl was noted. The interaction energies vary with the interaction pattern and facet. The (010) facet has the greatest interaction energy, followed by (001) and (100), which results from the different arrangements of $\mathrm{Ca}$ ions on the facets. Although the formation of $\mathrm{CaOH}$ or $\mathrm{Ca}(\mathrm{OH})_{2}$ is controversial in the literature, we found that both are energetically favorable on the HAp surface. The former is more favorable on the (001) and (100) facets, and the latter is more favorable on the (010) facet. The addition of a water molecule tends to weaken the $\mathrm{Ca}-\mathrm{OH}$ interaction, but its interaction strength is weaker than that of $\mathrm{Ca}-\mathrm{OH}$. The interaction energy of $\mathrm{Ca}-\mathrm{OH}$ is also dependent on the interaction pattern and facet. Calculations on the stretching vibration of surface $\mathrm{Ca}-\mathrm{O}$ and $\mathrm{O}-\mathrm{H}$ confirmed the bonding between the surface $\mathrm{Ca}$ ion and hydroxyl. Our calculations reveal a strong $\mathrm{Ca}-\mathrm{OH}$ interaction on the Ca-rich HAp surface. Since HAp-based biomaterials are usually used in alkalescent physiological environment, the hydroxyl-coated surface structure is more appropriate than the Ca-terminated surface model for studying the surface activity of HAp toward biomolecules.

\section{Conflicts of interest}

There are no conflicts to declare.

\section{Acknowledgements}

The authors thank financial support from National High Technology Research and Development Program of China (No. 2015AA034202) and National Natural Science Foundation of China (No. 21373140). Part of the calculations were carried out at High Performance Computing Center of Sichuan University.

\section{References}

1 J. Reyes-Gasga, R. Garcia and L. Vargas-Ulloa, Philos. Mag. A, 1997, 75, 1023-1040.

2 L. A. Adams and E. R. Essien, J. Adv. Ceram., 2016, 5, 47-53.

3 P. Choudhury and D. C. Agrawal, Surf. Coat. Technol., 2011, 206, 360-365.

4 M. Wang, Biomaterials, 2003, 24, 2133-2151.

5 M.-H. Hong, D. S. Oh and Y.-K. Lee, Bone, 2011, 48, S186.

6 R. M. Rajachar, A. Q. Truong and C. M. Giachelli, J. Mater. Sci.: Mater. Med., 2008, 19, 3279-3285.

7 J. Zeglinski, M. Nolan, D. Thompson and S. A. M. Tofail, Surf. Sci., 2014, 623, 55-63.

8 H. Kheimehsari, S. Izman and M. R. Shirdar, J. Mater. Eng. Perform., 2015, 24, 2294-2302.

9 N. Almora-Barrios and N. H. De Leeuw, Cryst. Growth Des., 2012, 12, 756-763.

10 M. Yashima, Y. Yonehara and H. Fujimori, J. Phys. Chem. C, 2011, 115, 25077-25087.

11 H. Chappell, M. Duer, N. Groom, C. Pickard and P. Bristowe, Phys. Chem. Chem. Phys., 2008, 10, 600-606.

12 P. Rulis, H. Yao, L. Ouyang and W. Ching, Phys. Rev. B: Condens. Matter Mater. Phys., 2007, 76, 245410.

13 C. Jager, T. Welzel, W. Meyer-Zaika and M. Epple, Magn. Reson. Chem., 2006, 44, 573-580.

14 M. Ben Osman, S. Diallo-Garcia, V. Herledan, D. Brouri, T. Yoshioka, J. Kubo, Y. Millot and G. Costentin, J. Phys. Chem. C, 2015, 119, 23008-23020.

15 H. B. Lu, C. T. Campbell, D. J. Graham and B. D. Ratner, Anal. Chem., 2000, 72, 2886-2894.

16 C. A. Ospina, J. Terra, A. J. Ramirez, M. Farina, D. E. Ellis and A. M. Rossi, Colloids Surf., B, 2012, 89, 15-22.

17 K. Sato, T. Kogure, T. Ikoma, Y. Kumagai and J. Tanaka, Key Eng. Mater., 2000, 192, 283-286. 
18 M. Rivas, J. Casanovas, L. J. Del Valle, O. Bertran, G. RevillaLopez, P. Turon, J. Puiggalí and C. Alemán, Dalton Trans., 2015, 44, 9980-9991.

19 Q. Wang, M. Wang, K. Wang, Y. Liu, H. Zhang, X. Lu and X. Zhang, Biomed. Mater., 2015, 10, 032001.

20 W. Zhu and P. Wu, Chem. Phys. Lett., 2004, 396, 38-42.

21 L. J. Del Valle, O. Bertran, G. Chaves, G. Revilla-Lopez, M. Rivas, M. T. Casas, J. Casanovas, P. Turon, J. Puiggalí and C. Alemán, J. Mater. Chem. B, 2014, 2, 6953-6966.

22 A. Slepko and A. A. Demkov, J. Chem. Phys., 2013, 139, 044714.

23 N. Almora-Barrios, K. F. Austen and N. H. De Leeuw, Langmuir, 2009, 25, 5018-5025.

24 M. R. T. Filgueiras, D. Mkhonto and N. H. De Leeuw, J. Cryst. Growth, 2006, 294, 60-68.

25 A. Rimola, M. Corno, C. M. Zicovich-Wilson and P. Ugliengo, J. Am. Chem. Soc., 2008, 130, 16181-16183.

26 W. Zhao, Z. Xu, Y. Yang and N. Sahai, Langmuir, 2014, 44, 13283-13292.

27 M. Prakash, T. Lemaire, D. Di Tommaso, N. H. De Leeuw, M. Lewerenz, M. Caruel and S. Naili, Appl. Surf. Sci., 2017, 418, 296-301.

28 D. Zahn and O. Hochrein, Phys. Chem. Chem. Phys., 2003, 5, 4004-4007.

29 J. O'Young, Y. Liao, Y. Xiao, J. Jalkanen, G. Lajoie, M. Karttunen, H. A. Goldberg and G. K. Hunter, J. Am. Chem. Soc., 2011, 133, 18406-18412.

30 J.-W. Shen, T. Wu, Q. Wang and H.-H. Pan, Biomaterials, 2008, 29, 513-532.

31 T. T. Pham, T. Lemaire, E. Capiez-Lernout, M. Lewerenz, Q. D. To, J. K. Christie, D. Di Tommaso, N. H. de Leeuw and S. Naili, Theor. Chem. Acc., 2015, 134, 59.

32 S. E. Ruiz Hernandez, N. H. De Leeuw and I. Streeter, Phys. Chem. Chem. Phys., 2015, 17, 22377-22388.

33 S. Hokkanen, A. Bhatnagar, E. Repo, S. Lou and M. Sillanpää, Chem. Eng. J., 2016, 283, 445-452.

34 L. Chen, K.-S. Zhang, J.-Y. He, W.-H. Xu, X.-J. Huang and J.-H. Liu, Chem. Eng. J., 2016, 285, 616-624.

35 J. Brzezińska-Miecznik, P. Jeleń, K. Haberko, W. Mozgawa and M. Sitarz, Ceram. Int., 2017, 43, 12540-12545.

36 J. He, Y. Su, T. Huang, B. Jiang, F. Wu and Z. Gu, Colloids Surf., B, 2014, 116, 303-308.

37 A. Michelot, S. Sarda, C. Audin, E. Deydier, E. Manoury, R. Poli and C. Rey, J. Mater. Sci., 2015, 50, 5746-5757.

38 J. Zhang, X. Liu, T. Deng, P. Yao, H. Song, S. Zhou and W. Yan, J. Nanomater., 2015, 16, 145.

39 B. T. Mortensen, P. O. Jensen, N. Helledie, P. O. Iversen, E. Ralfkiaer, J. K. Larsen and M. T. Madsen, Br. J. Haematol., 1998, 102, 458-464.

40 D. H. Kohn, M. Sarmadi, J. I. Helman and P. H. Krebsbach, J. Biomed. Mater. Res., 2002, 60, 292-299.

41 J. Kolmas, D. Marek and W. Kolodziejski, Appl. Spectrosc., 2015, 69, 902-912.
42 L. Bertinetti, A. Tampieri, E. Landi, C. Ducati, P. A. Midgley, S. Coluccia and G. Martra, J. Phys. Chem. C, 2007, 111, 40274035.

43 K. Wang, M. Wang, Q. Wang, X. Lu and X. Zhang, J. Eur. Ceram. Soc., 2017, 37, 2509-2520.

44 T. Biktagirov, M. Gafurov, K. Iskhakova, G. Mamin and S. Orlinskii, J. Low Temp. Phys., 2016, 185, 627-632.

45 L. Bengtsson, Phys. Rev. B: Condens. Matter Mater. Phys., 1999, 59, 12301-12304.

46 G. Kresse and J. Furthmüller, Comput. Mater. Sci., 1996, 6, 15-50.

47 J. P. Perdew, K. Burke and M. Ernzerhof, Phys. Rev. Lett., 1996, 77, 3865-3868.

48 G. Kresse and J. Hafner, Phys. Rev. B: Condens. Matter Mater. Phys., 1993, 47, 558-561.

49 G. Renaudin, P. Laquerriere, Y. Fillinchuk, E. Jallot and J. M. Nedelec, J. Mater. Chem., 2008, 18, 3593-3600.

50 R. Astala and M. J. Stott, Phys. Rev. B: Condens. Matter Mater. Phys., 2008, 78, 075427.

51 G. Ulian, D. Moro and G. Valdre, J. Appl. Crystallogr., 2016, 49, 1893-1903.

52 D. Mei, J. Phys. Chem. C, 2010, 114, 1867-1874.

53 N. H. De Leeuw, J. Mater. Chem., 2010, 20, 5376-5389.

54 F. Chiatti, M. Delle Piane, P. Ugliengo and M. Corno, Theor. Chem. Acc., 2016, 135, 54.

55 J. C. Elliot, Structure and Chemistry of the Apatites and Other Calcium Orthophosphates, Elsevier, Amsterdam, 1994, pp. 1-404.

56 S. Diallo-Garcia, M. Ben Osman, J.-M. Krafft, S. Casale, C. Thomas, J. Kubo and G. Costentin, J. Phys. Chem. C, 2014, 118, 12744-12757.

57 V. Bolis, C. Busco, G. Martra, L. Bertinetti, Y. Sakhno, P. Ugliengo, F. Chiatti, M. Corno and N. Roveri, Philos. Trans. R. Soc., A, 2012, 370, 1313-1336.

58 J. P. Simmer and A. G. Fincham, Crit. Rev. Oral Biol. Med., 1995, 6, 84.

59 T. Kobayashi, S. Ono, S. Hirakura, Y. Oaki and H. Imai, CrystEngComm, 2012, 14, 1143-1149.

60 S. Diallo-Garcia, M. Ben Osman, J.-M. Krafft, S. Boujday and C. Guylène, Catal. Today, 2014, 226, 81-88.

61 S. Nakamura, H. Takeda and K. Yamashita, J. Appl. Phys., 2001, 89, 5386-5392.

62 H.-T. Chen, Y. M. Man Choi, M. Liu and M. C. Lin, ChemPhysChem, 2007, 8, 849-855.

63 S. P. Walch, C. M. Rohlfing, C. F. Melius and C. W. Bauschlicher Jr, J. Chem. Phys., 1988, 88, 6273-6281.

64 E. Balan, S. Delattre, D. Roche, L. Ségalen, G. Morin, M. Guillaumet, M. Blanchard, M. Lazzeri, C. Brouder and E. K. H. Salje, Phys. Chem. Miner., 2011, 38, 111-122.

65 H. Tanaka, T. Watanabe and M. Chikazawa, J. Chem. Soc., Faraday Trans., 1997, 93, 4377-4381.

66 M. Corno, C. Busco, B. Civalleri and P. Ugliengo, Phys. Chem. Chem. Phys., 2006, 8, 2464-2472.

67 G. Ulian, G. Valdre, M. Corno and P. Ugliengo, Am. Mineral., 2013, 98, 752-759. 